\title{
PERCEPÇÃO DE QVT EM AGÊNCIA REGULADORA DE SERVIÇOS
}

\author{
Perception of QWL in Regulatory Agency Services \\ Perception de QVT dans Agence de Réglementation de Services \\ Percepción de CVT en Agencia Reguladora de Servicios
}

Romildo Garcia Brusiquese ${ }^{1}$

Doutorado e Mestrado em Psicologia Social, do Trabalho e das Organizações (Universidade de Brasília

- UnB); MBA em Gestão Empresarial (FGV); Especialização em Engenharia de Segurança do Trabalho

(Universidade de Franca); Graduação em Engenharia Civil (Fesp/Uemg).

\begin{abstract}
Mário César Ferreira ${ }^{2}$
Doutorado em Ergonomia (Ecole Pratique des Hautes Etudes, EPHE, França); Mestrado em Psicologia (Universidade de Brasília - UnB); Especialização em Psicologia Social (FUCMT); Formação em Psicologia

(FUCMT).

Veruska Albuquerque Pacheco $^{3}$

Doutorado e mestrado em Psicologia Social, do Trabalho e das Organizações (Universidade de Brasília - UnB); Especialização em Gestão de Negócios em Turismo (Universidade de Brasília - UnB); Graduação em Administração (Centro Universitário de Brasília - UniCEUB).
\end{abstract}

\section{RESUMO}

Este estudo objetivou verificar a percepção de trabalhadores de uma agência reguladora de serviços no Brasil quanto à qualidade de vida no trabalho (QVT). A amostra foi de 1.062 participantes, que responderam ao Inventário de Avaliação de Qualidade de Vida no Trabalho (IA_QVT), aplicado no formato digital. Os resultados indicaram avaliação favorável dos fatores Condições de Trabalho, Relações Socioprofissionais de Trabalho e Elo Trabalho-Vida Social e desfavorável nos fatores Organização do Trabalho e Reconhecimento e Crescimento Profissional, os quais se caracterizam por ações sob domínio do empregador. Conforme hipótese proposta, a avaliação de QVT se posicionou em zona de transição da cartografia do IA_QVT, indicando necessidade de atuação prioritária nos fatores mais críticos. Sugere-se a realização de novos estudos para ampliar as análises desse recém-surgido campo de trabalho.

Palavras-chave: Qualidade de vida no trabalho; ergonomia; gestão de pessoas.

\begin{abstract}
This study aimed to verify the employees' perception of quality of working life (QWL) in a regulatory agency services in Brazil. The survey relied on sample of 1,062 participants, all of whom responded to the Inventory of Evaluation of Quality of Working Life that was applied in the digital format. Results indicated favorable assessment of the factors Working Conditions; Socio-professional Relationships at Work; and Work-Social Life
\end{abstract}

\footnotetext{
${ }^{1}$ brusiquese@outlook.com

2 mcesar@unb.br

3 albuquerque.veruska@gmail.com
} 
Link and unfavorable in Work Organization and Professional Growth and Recognition, both characterized by actions under the employer's domain. Aligned to the proposed hypothesis, the overall assessment of QWL positioned itself in the transition zone of the map of the instrument, indicating the need for priority action on critical factors. It is suggested to conduct new studies to extend the analysis of this newly emerged labour camp.

Keywords: Quality of working life; ergonomics; human resource management.

\section{RÉSUMÉ}

Le but de la recherce a eu d'identifier les répresentations des agents travaillant dans une unité governamentale de surveillance de la qualité des services publiques au Brésil en ce qui concerne la thématique qualité de vie au travail (QVT). Ont participé de la recherche l'echantillon de 1062 travailleurs qui ont répon du l'Inventaire d'Évaluation de la Qualité de Vie au Travail (IA_QVT), aplique en ligne dans une site. Les résultats indiquent une évalution plutôt favorable des facteurs "Conditions de Travail", "Rapports Sociaux de Travail", et "Lien Travail-Vie Sociale" et en revanche une évalution défavorable concernant les facteurs "Organisation du Travail" et "Reconnaissance et Développment Professionel" qui, dans ce cas, sont sous la charge des employeurs. D'après l'hypothèse posée, l'évalution de QVT s'est placée dans une zonne intermédiare de la carthographie psicométrique de l'IA_QVT, en soulignant la necessite d'agir sous les facteurs plutôt critiques. De nouvelles études sont suggerés pour élargir les analyses dans ce nouveau champ d'investigation.

Mots-clés: qualité de vie au travail; ergonomie; gestion du personnel.

\section{RESUMEN}

Este estudio tuvo como objetivo verificar la percepción de trabajadores de una agencia reguladora de servicios en el Brasil con respecto a la calidad de vida en el trabajo (CVT). La muestra fue de 1,062 participantes que respondieron al Cuestionario de Evaluación de Calidad de Vida en el Trabajo que se aplicó en formato digital. Los resultados indicaron una evaluación favorable de los factores Condiciones de Trabajo, Relaciones Socioprofesionales de Trabajo, y Vínculo Trabajo-Vida Social; y desfavorable en los factores Organización del Trabajo y Reconocimiento y Crecimiento Profesional, los cuales se caracterizan por acciones bajo dominio del empleador. Según la hipótesis propuesta, la evaluación de la CVT se posicionó en zona de transición de la cartografía del instrumento, indicando la necesidad de actuación prioritaria en los factores más críticos. Se sugiere la realización de nuevos estudios para ampliar el anális is de este recién surgido campo de trabajo.

Palabras clave: calidad de vida en el trabajo; ergonomía; gestión de personas.

\section{INTRODUÇÃO}

O cenário produtivo desse início de século tem se mostrado fortemente influenciado por uma quantidade crescente de novos fatores que impactam a realização do trabalho, em especial no setor de serviços, em que o advento das novas tecnologias da informação e da comunicação se apresenta como agente de recrudescimento da intensificação e do controle do trabalho. Paralelamente a esse fenômeno, tem-se verificado o surgimento de novos setores e ocupações profissio na is que buscam dar conta de demandas que eclodem de um contexto em que as organizações se veem sob a pressão de dispositivos regulatórios mais rígidos, assim como de uma sociedade mais consciente de seus direitos.
Durante as décadas de 1990 e de 2000, foram criadas no Brasil as agências nacionais de regulação de serviços. Entidades integrantes da administração federal indireta, as agências reguladoras foram concebidas com a finalidade de regular ou supervisionar, em suas respectivas esferas e atribuições, as atividades de prestação de serviços e de exploração da estrutura disponível. Constituem, também, objetivos das agências, implementar politicas formuladas pelos órgãos de governo, por exemplo, ministérios, em cada área de atuação, bem como harmonizar, preservado o interesse público, os objetivos dos usuários e das empresas concessionárias, entre outros intervenientes e, ainda, arbitrar conflitos de interesses e impedir situações que configurem competição imperfeita ou 
infração da ordem econômica (Lei $\mathrm{n}^{\mathrm{o}}$ 10.233, 2001).

De forma semelhante ao que tem ocorrido com diversas outras atividades econômicas, no setor de agências reguladoras se tem tratado os efeitos da chamada reestruturação produtiva ${ }^{4}$ com iniciativas visando adaptações na estrutura e nas formas de trabalho atuais, tanto na gestão, quanto na operação. Segundo Antunes (2012), esse fenômeno tem início na década de 1980, quando novos padrões organizacionais e tecnológicos, assim como novas formas de organização social do trabalho, passaram a ser adotados pelas empresas.

As novas formas de relação com o público consumidor, balizadas pela busca desenfreada das empresas por conquista e retenção de clientes com o objetivo maior de domínio e consolidação do mercado, têm trazido consequências aparentemente não pensadas pelos empresários e gestores: o impacto que as formas de introdução das inovações promovem nas condições em que o trabalho é realizado pelos empregados. Se por um lado, a previsão desse efeito não foi possível, por outro, tem-se a urgência de seu tratamento, uma vez que sinais de sua presença podem ser percebidos no âmbito do cenário produtivo atual, em especial nas grandes organizações.

As instituições públicas, por sua vez, não estão alheias a esse processo de transformação do trabalho. Inseridas em um contexto onde prevalece postura mais vigilante e reivindicatória dos usuárioscontribuintes quanto à qualidade dos serviços prestados (Ferreira, 2016), elas tendem a se espelhar na atuação das organizações privadas e reproduzem $\mathrm{o}$ mesmo quadro de busca obstinada por resultados sem o adequado tratamento das condições em que os trabalhadores desenvolvem suas atividades.

\footnotetext{
${ }^{4}$ Reestruturação produtiva e industrial: processo caracterizado, segundo Baumgarten (2006), pela compatibilização de mudanças institucionais e
}

Uma das estratégias adotadas pelas organizações para amenizar esse quadro de deterioração da realidade laboral, no qual muitas vezes se produz nos limites da resistência dos trabalhadores, tem sido identificada por iniciativas de implantação de práticas antiestresse sob a denominação de programas de qualidade de vida no trabalho (QVT). De natureza voltada para a restauração corpo-mente, as práticas geralmente buscam atuação no âmbito do indivíduo em detrimento do enfrentamento das inadequações do contexto organizacional. Conforme apontam Ferreira (2012) e Ferreira, Antloga, Paschoal e Ferreira (2013), os resultados obtidos com a implementação dessas práticas, as quais se caracterizam pelo viés predominantemente assistencialista, trazem, muitas vezes, pouca efetividade em razão da baixa adesão dos trabalhadores aos programas, uma vez que os elementos que estão na origem das fontes de mal-estar no trabalho não são tratados. Segundo Ferreira (2016), resultados de pesquisas realizadas pelo Grupo de Estudos em Ergonomia Aplicada ao Setor Público (ErgoPublic), da Universidade de Brasilia, com servidores públicos federais, mostram que não são encontradas referências a tais práticas no discurso dos entrevistados quando apresentam sua definição para QVT.

\section{Qualidade de Vida no Trabalho}

O tema qualidade de vida no trabalho tem recebido atenção crescente desde suas primeiras abordagens, a exemplo do modelo de Walton, na década de 1970 , conforme citado em Limongi-França (2012), que incluía, entre outras questões, oportunidades de desenvolvimento e de crescimento, integração social e condições de trabalho seguras e saudáveis. Estes fatores também são encontrados em pesquisas mais recentes, como no estudo de

organizacionais nas relações de produção e de trabalho em que a introdução das novas tecnologias informatizadas tem tido desempenho fundamental. 
May, Lau e Johnson (1999) que, em sua revisão da literatura sobre o tema, destacam, como conceitos-chaves, segurança no emprego, melhores sistemas de recompensa, oportunidade de crescimento, grupos participativos e aumento da produtividade organizacional, entre outros.

$\mathrm{Na}$ visão de Ferreira (2016), a abordagem de QVT deve contribuir para se alcançar, concomitantemente, três dimensões interdependentes: (a) vigilânc ia em saúde e segurança no trabalho; (b) assistência psicossocial aos trabalhadores; e (c) promoção do bem-estar no trabalho. Em certa medida, corroborando com tal perspectiva, Ramstad (2008) acrescenta que a produtividade sustentável se refere ao incremento de produtividade que não se obtém a expensas do bem-estar do trabalhador. Assim, o desempenho de empresas que aplicam sistematicamente práticas de gestão e organização pode thes possibilitar melhorias na QVT, na remuneração e no reconhecimento aos trabalhadores por evolução nas habilidades; oferecer mais formação e promoção de oportunidades; e demitir menos durante crises econômicas. Em um cenário em que se verificam empresas atuando dessa forma, o desenvolvimento organizacional pode produzir benefícios para os indivíduos, para as organizações e para o sistema econômico e social.

Na análise de Ferreira (2012), os fatores que estão na gênese das vivências de bem-estar e mal-estar no trabalho são: (a) as condições de trabalho, que expressam as condições físicas, materiais e instrumentais, como espaço, iluminação, temperatura, equipamentos, mobiliário, entre outros; (b) a organização do trabalho, que compreende as variáveis de tempo, de controle e características da tarefa, como pausas, ritmo, fiscalização etc.; (c) as relações socioprofissionais de trabalho, que se referem às interações sociais e comunicação no trabalho; (d) o reconhecimento e crescimento profissional, relativo ao reconhecimento no trabalho (p. ex., dedicação, resultado alcançado) e ao crescimento profissional (p. ex., oportunidades, equidade); e (e) o elo entre trabalho e vida social, que se refere às percepções sobre a instituição, o trabalho e as analogias com a vida social que influenciam a atividade de trabalho.

\section{Problema e Objetivo de Pesquisa}

De posse do delineamento do atual cenário produtivo, caracterizado especialmente pela profusão de transformações oriundas da introdução de novas tecnologias e consequentes impactos nas formas de gestão do trabalho, entender como se caracterizam e como atuam as organizações emergidas desse novo quadro econômico representa importante alternativa para estudos e pesquisas relacionados a esse novo capítulo do mundo do trabalho. Nesse sentido, o contexto de trabalho de uma agência reguladora de serviços, analisado no presente estudo, foi extraído de um recorte do grupamento de novas organizações que se apresentam, ainda, como campo de pesquisa pouco explorado no país.

Assim, a influência desse contexto produtivo - com seu quadro de intensificação das atividades a um ritmo ditado por forte fluxo informacional - na forma como os trabalhadores avaliam sua qualidade de vida no trabalho constitui o problema de pesquisa do presente estudo. Sob essa perspectiva, o objetivo desta pesquisa foi verificar as representações dos trabalhadores da organização pesquisada quanto à qualidade de vida no trabalho.

Em função de características desse recém-surgido campo de estudo das agências reguladoras - que remonta há cerca de duas décadas - tais como novo contexto de trabalho, novas práticas de gestão e novas possibilidades de ascensão profissional, o que enseja, portanto, potenciais aspectos positivos, espera-se, como hipótese geral de pesquisa, que a avaliação da QVT na organização pesquisada seja globalmente positiva. 
Ergonomia da Atividade

O referencial teórico adotado na pesquisa foi a Ergonomia da Atividade, que, segundo Ferreira e Mendes (2003), se refere à abordagem científica que investiga a relação entre os indivíduos e o contexto de produção e que tem, como objetivo principal, compreender os indicadores críticos presentes nesse contexto para transformá-los de forma a atender às necessidades e aos objetivos de trabalhadores, gestores, usuários e consumidores. Sob essa perspectiva, Guérin, Laville, Daniellou, Duraffourg e Kerguelen (2001) sustentam que transformar o trabalho é a finalidade primeira da ação ergonômica e que essa transformação deve ser realizada de forma a: (a) contribuir para a concepção de situações de trabalho que não alterem a saúde dos trabalhadores, possibilitando o exercício de suas competências de forma individual e coletiva, com possibilidades de valorização de suas capacidades; e (b) alcançar os objetivos econômicos determinados pela empresa, em função dos investimentos realizados ou futuros.

Para que a transformação do trabalho ocorra de forma a resguardar o interesse de ambos os partícipes, a organização e os trabalhadores, necessário se faz compreender a realidade laboral, na qual, nas palavras de Tersac e Maggi (2004), a atividade se desprende das condições de trabalho consideradas como dadas, entre as quais, a organização. Sob essa perspectiva, a análise da atividade mostra que a situação de trabalho é mutável, variável, ativa e que requer, portanto, novos olhares, especialmente sob as lentes dos executores das tarefas que confrontam, diariamente, as dificuldades decorrentes da distância entre o que foi concebido pela organização e o que se traduzirá em produto do trabalho.

O cenário produtivo da era informatizada, a exemplo do que se verifica no ambiente das agências reguladoras, congrega em um modelo híbrido, elementos tradicionais, como sistemas hierárquicos funcionais e controle temporal de produção, de um lado e intenso fluxo informacional com suporte nas modernas plataformas da tecnologia da informação e da comunicação, de outro. Entre os diversos elementos de transformação do trabalho, a informática e a automação, conforme destacam Falzon e Sauvagnac (2007), aumentam a demanda mental das atividades, reforçando, portanto, a importância de uma investigação das representações dos trabalhadores com relação à qualidade de vida no trabalho.

\section{Relevância da Pesquisa}

A importância do presente estudo é percebida pela possibilidade de geração de benefícios a trabalhadores, organizações e sociedade, uma vez que serão disponibilizados achados científicos que podem contribuir com a melhoria das condições de trabalho, com reflexos na otimização dos resultados corporativos e, consequentemente, na qualidade dos produtos e serviços disponibilizados para consumo. Noâmbito acadêmico, percebe-se a relevância da pesquisa quando se vislumbra possibilidades de contribuição para o surgimento de novas discussões e estudos com foco na melhoria da qualidade de vida no trabalho em diversas atividades econômicas.

\section{Método}

\section{Participantes}

Foi realizado censo com os 2.307 trabalhadores da organização presentes no período da coleta de dados, dos quais 1.172 participaram da pesquisa, quando foi obtido um retorno de 1.062 questionários válidos $(46,03 \%)$, o que constituiu a amostra da pesquisa. Foram declarados, quanto a gênero, 370 mulheres e 614 homens; a faixa etária predominante $(24 \%)$ foi de 30 a 34 anos, $61 \%$ com formação superior completa, todos funcionários de uma agência reguladora de serviços com sede no 
Distrito Federal e com representações em todos os estados brasileiros, com tempo médio na organização de 4,06 anos. Contribuíram, para a composição da amostra, trabalhadores do quadro efetivo, terceirizados, estagiários, incluindo detentores de cargos de gestão.

\section{Instrumentos}

Para a coleta dos dados, foi utilizado o Inventário de Avaliação de Qualidade de Vida no Trabalho (IA_QVT), desenvolvido por Ferreira (2009), destinado ao diagnóstico e monitoramento de qualidade de vida no trabalho. Trata-se de instrumento científico de pesquisa validado, desenvolvido com base em pesquisas do Grupo de Estudos em Ergonomia Aplicada ao Setor Público (ErgoPublic), do Instituto de Psicologia, da Universidade de Brasília.

$\mathrm{O}$ instrumento possui natureza quantitativa e qualitativa. Para a parte quantitativa, é utilizada escala psicométrica do tipo Likert que varia de zero (discordância total) a 10 (concordância total), que possibilita conhecer o que pensam os respondentes sobre os fatores em análise, que são: (a) Condições de Trabalho (alfa ${ }^{5}$ 0,90), contendo 12 itens (exemplo: “o nível de iluminação é suficiente para executar as atividades"); (b) Organização do Trabalho (alfa 0,73), com nove itens (exemplo: "as normas para execução das tarefas são rígidas"); (c) Relações Socioprofissionais de Trabalho (alfa 0,89), composto por 16 itens (exemplo: "a convivência no ambiente de trabalho é harmoniosa"); (d) Reconhecimento e Crescimento Profissional (alfa 0,91), com 14 itens (exemplo: "falta apoio das chefias para o meu desenvolvimento profissional"); e (e) Elo Trabalho-Vida Social (alfa 0,80), contendo 10 itens (exemplo: "o trabalho que faço é útil para a sociedade"). A Figura 1 apresenta um exemplo de item do IA_QVT, a escala de avaliação, bem como a cartografia psicométrica utilizada para a interpretação dos resultados.

\section{Exemplo de item do IA_QVT}

\section{O local de trabalho é confortável}

Discordo totalmente

\begin{tabular}{|c|c|c|c|c|c|c|c|c|c|}
\hline & & & & & 5 & & & & \\
\hline$\cdots$ & $\cdots$ & - & - & $\begin{array}{l}\text { Tendência } \\
\text { Negativa }\end{array}$ & $\begin{array}{l}\text { Tendência } \\
\text { Positiva }\end{array}$ & + & ++ & +++ & ++++ \\
\hline Mal-Es & Intenso & Mal-Es & lerado & & & Bem-E & Moderado & Bem-E & r Intenso \\
\hline & Mal-Est & ominan & & & & & Bem-Este & ominant & \\
\hline $\begin{array}{l}\mathrm{Re} \\
\text { predomi } \\
\text { no trab } \\
\text { transfe }\end{array}$ & $\begin{array}{l}\text { ado neg. } \\
\text { cia de re } \\
\text { o. Repres } \\
\text { adas no } \\
\text { isco de }\end{array}$ & $\begin{array}{l}\text { que ev } \\
\text { entaçõe } \\
\text { açôes qL } \\
\text { jente or } \\
\text { oecime }\end{array}$ & $\begin{array}{l}\text { l-estar } \\
\text { n ser } \\
\text { onal. }\end{array}$ & $\begin{array}{l}\text { Resultad } \\
\text { Indic: } \\
\text { "situaçấ } \\
\text { Coexistên } \\
\text { estar e be } \\
\text { trab } \\
\text { Estado }\end{array}$ & $\begin{array}{l}\text { mediano. } \\
\text { dor de } \\
\text { o-limite". } \\
\text { cia de mal- } \\
\text { m-estar no } \\
\text { alho. } \\
\text { de alerta }\end{array}$ & $\begin{array}{r}\text { predor } \\
\text { no tr } \\
\text { m }\end{array}$ & $\begin{array}{l}\text { Itado posit } \\
\text { cia de repr } \\
\text { o. Repres } \\
\text { as e cons } \\
\text { organ } \\
\text { Promoç }\end{array}$ & $\begin{array}{l}\text { que evid } \\
\text { ntações } \\
\text { ições que } \\
\text { adas no } \\
\text { cional. } \\
\text { de Saúd }\end{array}$ & $\begin{array}{l}\text { cia a } \\
\text { bem-estar } \\
\text { evem ser } \\
\text { biente }\end{array}$ \\
\hline
\end{tabular}

Figura 1: Escala de avaliação tipo Likert, exemplo de item do IA_QVT e cartografia psicométrica, conforme "Qualidade de vida no trabalho: Uma abordagem centrada no olhar dos trabalhadores", por M. C. Ferreira, 2012, Brasília, DF: Paralelo 15 .

A parte qualitativa é composta por quatro questões abertas: (a) ' $\mathrm{Na}$ minha opinião qualidade de vida no trabalho é..."; (b) "Quando penso no meu trabalho no

\footnotetext{
5 Alfa de Cronbach: medida de confiabilidade das escalas que compõem o instrumento IA_QVT.
} 
[nome do órgão], o que me causa mais bemestar é..."; (c) "Quando penso no meu trabalho no [nome do órgão], o que me causa mais mal-estar é..."; e (d) "Comentários e sugestões".

\section{Procedimentos}

A coleta de dados, que ocorreu durante o período de 12/06/2012 a 03/07/2012, consistiu na aplicação do inventário no formato digital, com link para o endereço eletrônico do ErgoPublic, acessado pelos participantes por meio de códigos pessoais únicos, aleatoriamente distribuídos em impresso lacrado. Somente após a leitura das informações sobre o objetivo da pesquisa e instruções para o preenchimento do instrumento, além da assinatura eletrônica do participante relativa ao "consentimento livre esclarecido", é que era disponibilizado o campo para digitação do código.

O instrumento explicitava, também, diretrizes éticas relativas: (a) à participação voluntária; (b) à possibilidade de desistência em participar da pesquisa a qualquer tempo, sem acarretar nenhum prejuízo ou dano pessoal; (c) à inexistência de riscos para as atividades de trabalho ou para o órgão; (d) ao sigilo ético no tratamento dos resultados, com análise agrupada para fins de avaliação; e (e) à liberdade para não se identificar.

Para o tratamento dos dados quantitativos, foi utilizado o aplicativo SPSS (Pacote Estatístico para as Ciências Sociais), que gera resultados descritivos e possibilita análises inferenciais. Para a parte qualitativa, foi utilizado o software Alceste (Análise Lexical de Contexto de um Conjunto de Segmentos de Textos), desenvolvido por Max Reinert, consoante informam Bauer e Gaskell (2002), que permite identificar as informações essenciais das respostas às questões abertas a fim de extrair os Núcleos Temáticos Estruturadores do Discurso.

\section{Resultados}

Os resultados obtidos após a coleta e tratamento dos dados são apresentados a seguir, buscando responder à questão central da pesquisa, qual seja verificar o que pensam os trabalhadores quanto à sua qualidade de vida no trabalho. Nesse sentido, em consonância com a Tabela 1, serão apresentados os resultados das avaliações dos fatores que constituem $o$ IA_QVT, seguidos de exemplos de verbalizações dos respondentes associadas a essas avaliações e da avaliação global de QVT na organização pesquisada.

As verbalizações foram obtidas da análise dos núcleos temáticos estruturadores do discurso, disponibilizados pelo tratamento do Alceste, dos quais, citam-se aqueles que apresentaram relação com a análise quantitativa: Condições de Trabalho Adequadas; Melhorias na Climatização; Satisfação e Liberdade no Trabalho; Sobrecarga e Repetitividade das Tarefas; Participação nos Processos Decisórios e Efetividade da Regulação; Necessidade de Segurança e Estrutura Física nos Postos de Fiscalização; Relações Socioprofissionais Saudáveis, Dificuld ades nas Relações Socioprofissionais entre Pares; Reconhecimento e Crescimento Profissional; Valorização Profissional e Igualdade; Estabilidade; Salário Adequado e Possibilidade de Aprender; Falta de Reconhecimento, Desigualdade e Injustiça na Distribuição de Cargos; Ocupação de Cargos por Servidores de Carreira; Qualidade e Utilidade dos Serviços Prestados à Sociedade; e Prazer e Satisfação com o Trabalho.

Tabela 1

\begin{tabular}{l|c|c|c|c|c|c}
\hline \multicolumn{7}{c}{ Estatís ticas descritivas - Fatores e QVT } \\
\hline & CT & OT & RST & RCP & ETVS & QVT \\
\hline Média & 6,45 & 4,65 & 6,32 & 4,62 & $\mathbf{6 , 9 3}$ & 5,80 \\
\hline
\end{tabular}




\begin{tabular}{l|l|l|l|l|l|l}
\hline $\begin{array}{l}\text { Desvio } \\
\text { Padrão }\end{array}$ & 2,09 & 1,50 & 1,89 & 2,52 & 1,76 & 1,42 \\
\hline
\end{tabular}

Nota. Médias e desvios-padrão (DP) das avaliações dos fatores Condições de Trabalho (CT), Organização do Trabalho (OT), Relações Socioprofissionais de Trabalho (RST) Reconhecimento e Crescimento Profissional (RCP) e Elo Trabalho-Vida Social (ETVS) e da avaliação global de QVT. Em destaque, os fatores com menor e maior avaliação.

\section{Condições de Trabalho}

A avaliação média das "Condições de Trabalho" pelos participantes foi de 6,45 (DP $=2,09$ ), situando-se na zona de bemestar dominante, nos limites da modalidade de bem-estar moderado da cartografia psicométrica, o que representa um resultado positivo, indicando a predominância de percepções de bem-estar no trabalho. Pela análise dos itens que compõem esse fator, verificam-se, como mais bem avaliados: (a) "o nível de iluminação é suficiente para executar as atividades" [7,87]; (b) "o material de consumo é suficiente" [6,93]; e (c) "o local de trabalho é confortável" [6,82]. As menores médias foram para os itens: (a) "a temperatura ambiente é confortável" [5,10]; e (b) "o apoio técnico para as atividades é suficiente" [5,18].

Muito embora o fator "Condições de Trabalho" tenha obtido boa média na avaliação quantitativa, houve, na parte qualitativa, relatos de inadequações, como sistemas operacionais precários e climatização ineficiente do local de trabalho - ratificando as menores médias em itens correlatos acima citados - e dificuldades de transporte, elementos que contribuíram para as percepções de mal-estar no trabalho. A avaliação favorável do item "o local de trabalho é confortável" e a baixa avaliação do item "a temperatura ambiente é confortável" parece não indicar divergências importantes na avaliação sobre o ambiente físico de trabalho, uma vez que os valores atribuídos a esses itens se situaram próximos da média geral do fator, além do fato de que outros elementos, além da temperatura, contribuem para o conforto físico no ambiente de trabalho.

\section{Organização do Trabalho}

O fator "Organização do Trabalho" obteve avaliação média de 4,65 (DP = 1,50), situando-se na zona de transição da cartografia, com tendência negativa, indicando proximidade da zona de malestar dominante. Pela análise dos itens que compõem o fator, verificam-se, como mais bem avaliados: (a) "posso executar o meu trabalho sem sobrecarga de tarefas" [6,02]; (b) "falta tempo para ter pausa de descanso no trabalho", item invertido [5,94]; e (c) "posso executar o meu trabalho sem pressão" [5,78]. Os itens que registraram as menores médias, todos invertidos, foram: (a) "há cobrança de prazos para o cumprimento de tarefas" [2,71]; (b) "as tarefas são repetitivas" [3,10]; e (c) "existe fiscalização do desempenho" [3,82].

As baixas avaliações verificadas para os itens que abordam cobrança de prazos e fiscalização do desempenho poderiam indicar, a princípio, contradição com relação à avaliação mediana do item referente à inexistência de pressão no trabalho. Entretanto, entendeu-se que os baixos índices atribuídos na avaliação daqueles itens não indicariam, necessariamente, atribuição desfavorável importante de forma a considerá-los indicativo de existência de pressão intensa no trabalho. Dessa forma, caberia, também, interpretação no sentido de que os escores observados seriam indicativos de concordância com a existência, mas não seria sinalização da prevalência de práticas de intensos controle de prazos e fiscalização do desempenho no trabalho, o que, por outro lado, não descarta a necessidade de se aprofundar o estudo dessa questão no âmbito da organização pesquisada, com vistas à identificação de pontos a serem trabalhados para a melhoria das práticas de gestão do trabalho.

A parte qualitativa ratificou a avaliação dos respondentes de forma 
negativa do fator "Organização do Trabalho". Embora tenham sido constatados relatos de sentimentos de bemestar por se trabalhar com liberdade e autonomia, verbalizações indicando insatisfação no trabalho podem ser verificadas em referências à repetitividade das tarefas, o que ratifica a avaliação desse item na parte quantitativa, e também à inadequada estrutura de cargos, à influência política em decisões técnicas e à falta de segurança no contato com o cidadão a ser fiscalizado.

\section{Relações Socioprofissionais de Trabalho}

A média na avaliação do fator "Relações Socioprofissionais de Trabalho" foi de 6,32 (DP = 1,89), o que indica posicionamento na zona de bem-estar dominante, na modalidade de bem-estar moderado da cartografia. $\mathrm{O}$ resultado sinaliza a predominância de percepções de bem-estar no trabalho. A análise dos itens que compõem esse fator aponta, como mais bem avaliados: (a) "minhas relações de trabalho com os colegas são harmoniosas" [8,14]; (b) "é fácil o acesso à chefia imediata" [7,43]; e (c) "minhas relações de trabalho com a chefia são cooperativas" [7,38]. Como menos bem avaliados se destacam os itens: (a) "tenho livre acesso às chefias superiores" [4,86]; e (b) "a comunicação entre funcionários é insatisfatória", item invertido [5,07].

Os resultados da parte qualitativa mostraram relatos dos participantes alusivos ao bom e harmonioso relacionamento com colegas e superiores, confirmando as altas médias na avaliação quantitativa, embora tenham sido verificadas verbalizações sobre a existência de preconceito e discriminação entre colegas de categorias funcionais distintas, e de fofoca e boatos no ambiente de trabalho.

\section{Reconhecimento e Crescimento profissional}

O fator "Reconhecimento e Crescimento Profissional" teve avaliação média de 4,62 (DP = 2,52), indicando enquadramento na zona de transição, com tendência negativa, ou seja, com proximidade da zona de mal-estar dominante, conforme se pode verificar pela análise da cartografia psicométrica. Pela análise dos itens que compõem o fator, verificam-se, como mais bem avaliados: (a) "a prática do reconhecimento contribui para a minha realização profissional" [6,45]; e (b) "tenho a possibilidade de ser criativo no meu trabalho" [5,47]. Os itens com piores avaliações foram: (a) "as oportunidades de crescimento profissional são iguais para todos" [3,20]; (b) "a organização oferece oportunidade de crescimento profissional" $[3,64]$; e (c) "sinto-me reconhecido pela instituição onde trabalho" $[3,85]$.

Embora os participantes tenham efetuado relatos positivos com referência à boa remuneração e possibilidades de aprendizagem no trabalho, a baixa avaliação com relação a aspectos relacionados a crescimento profissional é reforçada em verbalizações alusivas a insatisfação quanto à falta de um plano adequado de progressão e promoção, e à ausência de servidores em posições de comando.

\section{Elo Trabalho-Vida Social}

A avaliação média que os participantes atribuíram ao fator "Elo Trabalho-Vida Social" foi de 6,93 (DP = $1,76)$, situando-se na zona de bem-estar dominante, na modalidade de bem-estar moderado, da cartografia. Pela análise dos itens que compõem o fator, verificam-se, como mais bem avaliados, os seguintes: (a) "sinto-me mais feliz no trabalho que com a minha família" [9,00]; (b) "sinto-me mais feliz no trabalho que em minha casa" [8,30]; e (c) "sinto-me mais feliz no trabalho que com os amigos" [8,19]. Houve, também, avaliação favorável do item "o trabalho que faço é útil para a sociedade" [7,28]. Os itens com pior avaliação foram: (a) "a sociedade 
reconhece a importância do meu trabalho" [4,21]; (b) "as atividades que realizo são fonte de prazer" [5,81]; e (c) "o tempo de trabalho que passo na organização me faz feliz" [5,81].

A análise de verbalizações dos participantes reforça os resultados da parte quantitativa da pesquisa no que se refere à associação da ideia de bem servir a sociedade com sentimentos de bem-estar no trabalho. A avaliação positiva quanto ao entendimento da utilidade do trabalho para a sociedade, contraposta com a avaliação desfavorável com relação ao reconhecimento desse trabalho pela sociedade, pode ser indicativo de necessidade de melhor divulgação dos serviços prestados pela agência reguladora objeto da presente pesquisa.

\section{Qualidade de Vida no Trabalho (QVT)}

Além da avaliação dos fatores anteriormente apresentados e da parte qualitativa dos dados, o IA_QVT possibilita, ainda, o cálculo da avaliação global de QVT, obtida pela média das avaliações dos cinco fatores. Essa média foi de 5,80 (DP = 1,42), o que a insere na zona de transição, com tendência positiva, conforme análise da cartografia psicométrica.

\section{Discussão}

A importância de elementos que remetem aos fatores Condições de Trabalho, Organização do Trabalho, Relações Socioprofissionais de Trabalho, Reconhecimento e Crescimento Profissional $_{2}$ e Elo Trabalho-Vida Social para a avaliação de qualidade de vida no trabalho é reconhecida no relato de diversas pesquisas sobre o tema. A aspiração com relação a reconhecimento e crescimento no trabalho, assim como sua importância na avaliação de QVT, podem ser verific adas no discurso de trabalhadores de diversos segmentos profissionais. Sob essa perspectiva, Rose, Beh, Uli e Idris (2006) apontam que ao longo de sua carreira, os trabalhadores buscam o crescimento e o desenvolvimento, o que seria uma noção de norte para a trajetória profissional.

Essa análise guarda consonância com a expectativa demonstrada pelos entrevistados da presente pesquisa por meio da boa avaliação que atribuíram ao item "a prática do reconhecimento contribui para a minha realização profissional", embora, de forma mais pontual, se verificou que os respondentes percebem de forma desfavorável itens relacionados a oportunidades de crescimento profissional e reconhecimento pela organização na qual trabalham. Assim, a avaliação positiva do item referente à contribuição da prática do reconhecimento na realização profissional oferece indicativos de uma aspiração relacionada a expectativas dos trabalhadores entrevistados quanto à sua carreira na organização.

Ainda, segundo os autores citados, QVT abarcaria as práticas de desenvolvimento de carreira utilizadas dentro da organização, tais como a colocação de expectativas claras quanto aos trabalhadores em suas aspirações e planos de sucessão. Assim, a QVT estaria vinculada ao desenvolvimento da carreira, ao tempo em que a carreira evoluiria com base na interação dos indivíduos dentro das organizações. Nesse sentido, as interações sociais no trabalho surgiriam como importantes elementos na catalisação desse processo de evolução na carreira.

A avaliação positiva com relação ao acesso à chefia imediata e a negativa, com relação às chefias superiores, verificadas no âmbito do fator Relações Socioprofissio nais de Trabalho, podem ser indicativos de barreiras para além do superior imediato, o que aponta para a necessidade de investigações nessa área pela organização pesquisada. Uma alternativa possível para se viabilizar essa comunicação entre diferentes níveis pode se dar pelo uso de recursos de tecnologia da informação, a exemplo de e-mails, os quais, segundo Orlikowski (2000), possibilitam a 
diminuição da hierarquia da estrutura de comunicação e o desvio dos canais convencionais para a interação com membros da alta administração.

Sobre a importância de questões relacionadas ao elo existente entre $\mathrm{o}$ trabalho e a vida social, Beauregard e Henry (2009) indicam que as práticas de conciliação entre trabalho e vida social terão um papel de auxiliar trabalhadores na compatibilização entre suas atividades profissionais e as demandas familiares, $\mathrm{o}$ que pode levar a um aumento significativo de sua produtividade e dos negócios da empresa. Práticas de permitir aos empregados a programação de seu tempo de forma a melhor equilibrar as demandas concorrentes do trabalho e de casa, auxiliando-os na obtenção de assistência de terceiros para o cumprimento de suas responsabilidades, são vistas com potencial para reduzir ou eliminar conflitos entre o trabalho e a vida social e, dessa forma, aumentar o desempenho profissional e a eficácia organizacional.

Com relação à organização do trabalho e às condições nas quais ele se desenvolve, Assunção (2008) aponta que o trabalho é influenciado pelas condições específicas do ambiente físico e organizacional no qual se desenvolve para produzir bens e serviços. As grandes organizações do setor de serviços - em especial aqueles realizados em escritórios sejam privadas ou públicas, têm caminhado para uma padronização do ambiente físico de trabalho, particularmente quanto a elementos como mobiliário, instalações, leiaute e recursos tecnológicos de comunicação e informação. Afora alguns elementos que podem ter sido percebidos como passíveis de melhoria, os dados obtidos na presente pesquisa para o fator Condições de Trabalho parecem indicar certa aquiescência, por parte dos respondentes, quanto aos recursos físicos disponíveis para o seu trabalho. Entretanto, com relação ao fator Organização do Trabalho, os resultados indicam avaliação diferente por parte dos entrevistados.
Pelas características do atual cenário global de produção, percebe-se que o elemento Organização do Trabalho tem reivindicado importância diferenciada, em especial, nas situações de trabalho onde prevalece o uso de computadores e sistemas informatizados. De acordo com Green (2004), em consonância com argumentos que ligam a mudança tecnológica à intensificação, trabalhos que requerem o uso de equipamentos computadorizados ou automatizados levam a níveis de esforço significativamente superiores. Assim, a baixa avaliação atribuída a itens relacionados à cobrança de prazos e à fiscalização de desempenho, assim como as verbalizações de entrevistados com referência à inadequação na relação entre a quantidade de tarefas e o reduzido tempo para a sua realização remetem a aspectos relacionados à intensificação e a um maior controle do trabalho, elementos cada vez mais característicos dos contextos de trabalho atuais.

\section{Conclusão}

Conforme apresentado nos resultados, a média da avaliação dos fatores do IA_QVT possibilitou a avaliação global de QVT, o que a posicionou na zona de transição da cartografia psicométrica utilizada nesta pesquisa, com tendência positiva, o que se alinha com a hipótese geral apresentada no início deste relato. Entretanto, a média encontra-se em uma zona preocupante, indicando a necessidade de atuação prioritária nos fatores apontados como mais críticos.

Os fatores Elo Trabalho-Vida Social e Relações Socioprofissionais de Trabalho, que têm componentes sociais como característica comum, apresentaram contribuição importante para a avaliação global mais favorável de QVT. Por sua vez, os fatores Organização do Trabalho e Reconhecimento e Crescimento Profissional, que se situam na esfera de ações sob domínio do empregador, foram os que mais contribuíram para a diminuição na 
avaliação da QVT, o que indica uma necessidade da organização de exercitar o olhar para dentro e verificar que ações de gestão em curso podem estar na origem dos fatores que desencadeiam a avaliação desfavorável de QVT. O fator Condições de Trabalho, avaliado de forma mais positiva e também fortemente dependente de ações do empregador, pode evidenciar acertos da organização e oferecer espelhamento para ações corretivas no âmbito da organização do trabalho e políticas de reconhecimento e crescimento no trabalho.

Embora os resultados encontrados nesta pesquisa indiquem proximidade com a hipótese geral apresentada, foram verificadas limitações com relação à melhor caracterização do contexto produtivo estudado, uma vez que as agências reguladoras de serviços ensejam recémsurgido campo de trabalho, ainda carente de estudos que abordem em profundidade seu aspecto organizacional. Nesse sentido, percebe-se o surgimento de espaço para novas pesquisas que possam ampliar as análises dessa nova forma de dedicação ocupacional.

Por fim, cabe assinalar que os resultados encontrados nessa investigação se inscrevem em um contexto singular $e$ recente do serviço público brasileiro. Contexto, certamente, portador de um perfil cultural (valores, crenças e práticas) ainda em processo de estruturação e consolidação se comparado com outros órgãos governamentais, alguns deles já seculares. Nesse sentido, os achados são próprios de um estudo de caso que fornece tão-somente as bases para novas investigações e, desta forma, não autorizam nenhum tipo de generalização dos resultados. Perspectiva que, aliás, não estava posta, desde o início, no delineamento dessa pesquisa.

\section{Referências}

Antunes, R. (2012). A nova morfologia do trabalho no Brasil: Reestruturação e precariedade. Nueva Sociedad, 232, 3-4.

Assunção, A. A. (2008). Saúde e mal-estar do(a) trabalhador(a) docente. Trabalho apresentado no VII Seminario de la Red de Estudios sobre Trabajo Docente - Nuevas regulaciones en América Latina, Buenos Aires.

Bauer, M. W., \& Gaskell, G. (2002). Pesquisa qualitativa com texto, imagem e som: Um manual prático (5 ed.). Petrópolis, RJ: Vozes.

Baumgarten, M. (2006). Reestruturação produtiva e industrial. In Dicionário de trabalho e tecnologia, 1, 237-239. Porto Alegre: UFRGS (Ed.).

Beauregard, T. A., Henry, L. C., (2009). Making the link between work-life balance practices and organizational performance. Human resource management review, 19, 9-22. doi: http://dx.doi.org/10.1016/j.hrmr.2008 .09 .001 .

Falzon, P., \& Sauvagnac, C. (2007). Carga de trabalho e estresse. In Blucher (Ed.), Ergonomia (pp. 141-154). São Paulo, SP: Editora Blucher.

Ferreira, M. C. (2009). Re: Inventário de avaliação de qualidade de vida no trabalho (Ia_qvt): Instrumento de diagnóstico e monitoramento de qvt nas organizações [Grupo de estudos online]. Extraído de http://www.ergopublic.com.br/?pg=d escricao_conteudo\& $\mathrm{id}=387 \&$ categoria $=8 \&$ subcat $=14$.

Ferreira, M. C. (2016). Qualidade de vida no trabalho: Uma abordagem centrada no olhar dos trabalhadores ( $3^{a}$ ed.). Brasilia, DF: Paralelo 15. 
Ferreira, M. C., Antloga, C., Paschoal, T., \& Ferreira, R. R. (2013). QVT é quando acordo... penso em vir trabalhar e o sorriso ainda continua no rosto. Sentidos da qualidade de vida no trabalho na ótica dos servidores públicos. In Paralelo 15 (Ed.), Qualidade de vida no trabalho. Questões fundamentais $e$ perspectivas de análise e intervenção (pp. 19-38). Brasília, DF: Paralelo 15.

Ferreira, M. C., \& Mendes, A. M. (2003). Trabalho e riscos de adoecimento: $O$ caso dos auditores-fiscais da previdência social brasileira. Brasilia, DF: Ler, Pensar, Agir.

Green, F. (2004). Work Intensification, Discretion, and the Decline in WellBeing at Work. Eastern Economic Journal, 30(4), 615-625.

Guérin, F., Laville, A., Daniellou, F., Duraffourg, J., \& Kerguelen, A. (2001). Bases para uma prática. In Edgard Blücher (Ed.), Compreender o trabalho para transformá-lo: A prática da ergonomia (pp. 47-68). São Paulo, SP: Edgard Blïcher Ltda.

Lei $\mathrm{n}^{\mathrm{o}}$ 10.233, Presidência da República, Casa Civil, Subchefia para Assuntos Jurídicos, (2001). Acesso em 25/09/2013 em

http://www.planalto.gov.br/ccivil_03/Leis/ LEIS_2001/L10233.htm.

Limongi-França, A. C. (2012). Fatores críticos da gestão de QVT: Retrospectiva conceitual. In Atlas (Ed.), Qualidade de vida no trabalho QVT: Conceitos e práticas nas empresas da sociedade pós-industrial (pp. 31-94). São Paulo, SP: Editora Atlas.

May, B. E., Lau, R. S. M., \& Johnson, S. K. (1999). A longitudinal study of quality of work life and business performance. Business Review, 58(2), 1-7.

Orlikowski, W. J. (2000). Using technology and constituting structures: a practice lens for studying technology in organizations. Organization Science, 11(4), 404-428.

Ramstad, E. (2008). Promoting performance and the quality of working life simultaneously. International Journal of Productivity and Performance Management, 58(5), 423-436. doi: 10.1108/17410400910965706.

Rose, R. C., Beh, L., Uli, J., \& Idris, K. (2006). An analysis of quality of work life (QWL) and career- related variables. American Journal of Applied Sciences, 3(12), 2151-2159.

Tersac, G., \& Maggi, B. (2004). O trabalho e a abordagem ergonômica. In Edgard Blücher (Ed.), A ergonomia em busca de seus princípios: Debates epistemológicos (pp. 79-104). São Paulo, SP: Edgard Blücher.

Data de submissão: 21/08/2017

Data de aceite: 20/10/2017 